\title{
Commentary: Surgical sequels in solid organ transplant
}

\author{
David L. Joyce, MD
}

From the Heart and Lung Transplantation Program, Medical College of Wisconsin, Milwaukee, Wis.

Disclosures: Author has nothing to disclose with regard to commercial support.

Received for publication Aug 2, 2019; accepted for publication Aug 2, 2019; available ahead of print Sept 9, 2019.

Address for reprints: David L. Joyce, MD, Medical College of Wisconsin, 8701 Watertown Plank Rd, Milwaukee,

WI 53226 (E-mail: djoyce@mcw.edu).

J Thorac Cardiovasc Surg 2020;160:710-1

0022-5223/\$36.00

Copyright (c) 2019 by The American Association for Thoracic Surgery

https://doi.org/10.1016/j.jtcvs.2019.08.025

\section{I don't know about doing a sequel. I think you can retroactively damage a product by adding to it.}

— Simon Pegg, English actor, comedian, screenwriter, and producer ${ }^{1}$

In contrast to Hollywood, the most spectacular surgical performances are rarely followed by an encore in the operating theater. In the case of solid organ transplantation, great lengths are usually undertaken by the selection committee to rule out any preexisting cardiac disease that could potentially impair the long-term durability of these "gifts of life." Nevertheless, an increasing number of transplant recipients from this growing and aging population are being referred for routine cardiac surgeries. Traditionally, these patients have been viewed cautiously as candidates for cardiac surgery, largely because of uncertainty about the added risks associated with immunosuppression and their underlying comorbidities. In their article in this issue of the Journal, "Outcomes in Patients with Solid Organ Transplants Undergoing Cardiac Surgery," Bianco and colleagues ${ }^{2}$ of the University of Pittsburgh Medical Center present some encouraging data that could support a more aggressive approach to cardiac surgery in these patients.

The types of transplants and subsequent cardiac surgeries in this study are quite diverse, which creates challenges in extrapolating the results to routine practice. Compounding this problem is the fact that the sample size for each patient subset is relatively small. For perspective, at the time of this writing, there have been more follow-up attempts in the Marvel universe than there have been repeat sternotomies in this study. Fortunately, the Society of Thoracic Surgeons risk assessment model can already collectively capture the unique constellation of risks facing these patients (with the notable exception of liver dysfunction, which presumably was not a major driver of adverse outcomes in this



See Article page 701. series). That said, the University of Pittsburgh Medical Center has vast experience in transplantation, and it may be naive to assume that the unique challenges occurring in the complicated cases of these immunosuppressed patients could be equally well addressed in a facility with less experience.

As a descriptive study, these findings could not address the benefits of pursuing alternative therapies. Much has changed in catheter-based therapies since 2011 (Figure 1), and it seems unlikely that many of the 20 patients who underwent open surgical aortic valve replacement would have been offered this procedure in $2019 .^{3}$ Although the 129 posttransplant patients were not compared with the remaining 11,061 patients with the full complement of native organs, it seems reasonable to assume that these patients were generally younger than those typically evaluated for routine cardiac surgery. In my own experience, youth can often improve tolerance for disagreeable circumstances, be they a second trip to the operating room or repeated viewings of certain Pixar franchises, such as Frozen.

Despite these limitations, the results described in this article represent a new benchmark for improved outcomes with cardiac surgery in the setting of a previous solid organ transplant when compared with previous studies. ${ }^{4,5}$ Bianco and colleagues ${ }^{2}$ are to be congratulated for their important work. It is to be hoped that these findings will further expand the benefits of transplantation. 


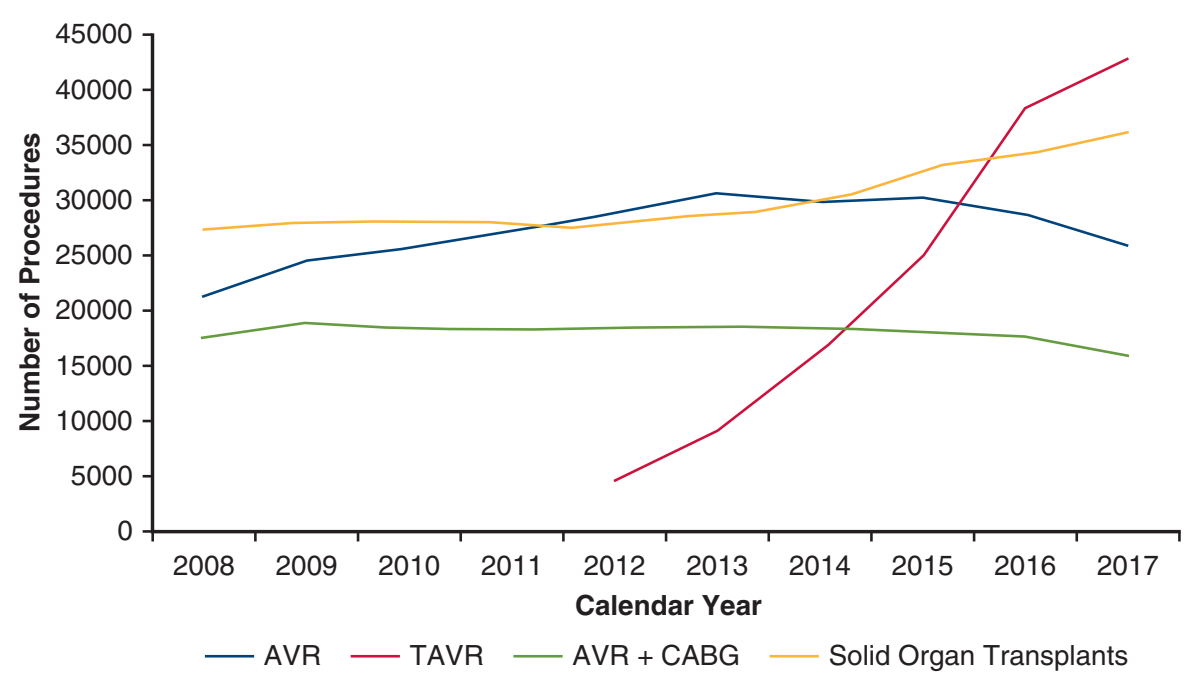

FIGURE 1. Changes in the number of solid organ transplants and aortic valve procedures in the United States, 2008 to 2017 . Data are from the United Network for Organ Sharing and the Society of Thoracic Surgeons databases. AVR, Aortic valve replacement; TAVR, transcatheter aortic valve replacement; $C A B G$, coronary artery bypass grafting. (Modified from D’Agostino and colleagues. ${ }^{6}$ )

\section{References}

1. Pegg S. Available at: https://www.allgreatquotes.com/quote-419410/. Accessed July $31,2019$.

2. Bianco V, Kilic A, Gleason TG, Aranda-Michel E, Harinstein ME, Thoma F, et al. Outcomes in patients with solid organ transplants undergoing cardiac surgery. J Thorac Cardiovasc Surg. 2020;160:701-7.

3. Mack MJ, Leon MB, Thourani VH, Makkar R, Kodali SK, Russo M, et al; PARTNER 3 Investigators. Transcatheter aortic-valve replacement with a balloon-expandable valve in low-risk patients. N Engl J Med. 2019;380:1695-705.
4. Kohmoto T, Osaki S, Kaufman DB, Leverson G, DeOliveira N, Akhter SA, et al Cardiac surgery outcomes in abdominal solid organ transplant recipients. Ann Thorac Surg. 2018;105:757-62.

5. Vargo PR, Schiltz NK, Johnston DR, Smedira NG, Moazami N, Blackstone EH, et al. Outcomes of cardiac surgery in patients with previous solid organ transplantation (kidney, liver, and pancreas). Am J Cardiol. 2015;116:1932-8.

6. D'Agostino RS, Jacobs JP, Badhwar V, Fernandez FG, Paone G, Wormuth DW et al. The Society of Thoracic Surgeons Adult Cardiac Surgery Database: 2019 update on outcomes and quality. Ann Thorac Surg. 2019;107:24-32. 